\title{
Survey of ophthalmic conditions in a Labrador community. I. Refractive errors
}

\author{
G. J. JOHNSON, A. MATTHEWS, AND E. S. PERKINS \\ From the Faculty of Medicine (Surgery), Memorial University of Newfoundland
}

SUMMARY Of the 745 available members of the population of Nain in Labrador $650(87 \%)$ were screened for refractive errors and ocular disease. Refraction by retinoscopy was done in 553 and axial length measured by an optical method in 514. The results showed that the incidence of low degrees of myopia was higher in Inuit (Eskimos) and those of Mixed Inuit-Caucasian blood in the age groups 10 to 40 than in those over $40.75 \%$ of the myopes came from 20 families in which myopia was present in 2 or more generations. Although there was no significant correlation between the refraction of parents and offspring, there were significant correlations between them for axial length. The axial lengths of the myopic eyes of the Inuit and Mixed populations were significantly longer than emmetropic and hypermetropic eyes. The younger members of the population were taller than their parents, and except in female Caucasians axial length showed a significant positive correlation with height. More myopes than emmetropes and hypermetropes achieved grade 8 or more in school. It is suggested that the increased incidence of myopia in the younger age groups might be due to environmental factors interfering with the process of emmetropisation in eyes with a genetic predisposition to myopia by virtue of inheriting a slightly longer eye. Better nutrition resulting in an increase in stature may also have had some influence.

There are now a number of reports of an increased incidence of myopia in the younger generations of North American Indians and Inuit (Eskimos) in Canada and Alaska (Young et al., 1969; Cass, 1973; Boniuk, 1973; Morgan and Munro, 1973; Woodruff and Samek, 1977). Surveys of such populations have shown few cases of myopia in the older population but incidences of 30 to $80 \%$ have been found in the 15 to 35 age groups, suggesting that environmental rather than genetic factors are concerned.

Data from routine eye clinics in Nain, Labrador, suggested that there was such an excess of myopia in this population, but as this apparent excess in the younger population might have been due to sampling errors it was decided to attempt a total population survey of refractive errors and other eye conditions in Nain during a regular 6-monthly eye clinic. The resident population of Nain, which lies at latitude $56^{\circ} 33^{\prime} \mathrm{N}$ on the coast of Labrador, consisted of 419 Inuit, 253 mixed Inuit and Caucasian, 89 Caucasian, and 12 of other ethnic origin making a total of 773 .

Address for reprints: Dr Gordon J. Johnson, Faculty of Medicine (Surgery), Memorial University of Newfoundland, St. Johns, Newfoundland, Canada A1B 3V6
28 Inuit were away seal hunting and were not available for examination.

Under the auspices of the International Grenfell Association and with the help and support of the Canadian National Institute for the Blind a team of ophthalmologists and a refracting optician visited Nain for 2 weeks in October 1977. The examinations were held in the Nursing Station, and in addition to the collection of data for the survey any necessary ophthalmic treatment was also provided.

\section{Patients and methods}

Those willing to attend for examination were given appointments, usually on a family basis, and a data sheet was made out for each person. The name, age, sex, height, and weight were completed by the nurse, and the people were then seen by one of the ophthalmologists, who performed keratometry and axial length measurements and also examined the optic disc for cupping and the presence of crescents round the disc. They were then refracted by the optician and finally examined on a Haag-Streit 900 slit-lamp microscope. In everyone over 40 , and 
Table 1 Age, sex, and race of Nain population surveyed (number not seen in parentheses)

\begin{tabular}{|c|c|c|c|c|c|c|c|c|c|c|c|c|}
\hline \multirow{3}{*}{$\begin{array}{l}\begin{array}{l}\text { Year of } \\
\text { birth }\end{array} \\
1967-77\end{array}$} & \multicolumn{4}{|c|}{ Inuit } & \multicolumn{4}{|c|}{ Mixed } & \multicolumn{2}{|c|}{ Caucasian } & \multicolumn{2}{|l|}{ Other } \\
\hline & \multicolumn{2}{|c|}{ Male } & \multicolumn{2}{|c|}{ Female } & \multicolumn{2}{|c|}{ Male } & \multicolumn{2}{|c|}{ Female } & Male & Female & \multirow{2}{*}{$\begin{array}{l}\text { Male } \\
\mathbf{3}\end{array}$} & \multirow{2}{*}{$\begin{array}{l}\text { Female } \\
0\end{array}$} \\
\hline & 49 & ( 5$)$ & 61 & (9) & 46 & ( 7$)$ & 45 & (5) & 6 & 14 & & \\
\hline $1957-66$ & 53 & (12) & 31 & ( 3$)$ & 32 & ( 3$)$ & 23 & (1) & 3 (3) & $8 \quad(1)$ & 2 & 2 \\
\hline $1947-56$ & 15 & (6) & 23 & (6) & 23 & ( 3$)$ & 14 & & $5 \quad(3)$ & 5 & 0 & 3 \\
\hline $1937-46$ & 15 & (4) & 15 & ( 2$)$ & 6 & (1) & 8 & (1) & 12 (1) & 4 (1) & 0 & 0 \\
\hline $1927-36$ & 14 & (6) & 14 & ( 5$)$ & 7 & & 6 & & 5 & 4 & 0 & 0 \\
\hline $1917-26$ & 8 & ( 2) & 6 & ( 1$)$ & 9 & & 6 & & 4 & 1 & 0 & 1 \\
\hline Pre-1917 & 14 & & 10 & & 3 & & 4 & & 4 & 3 & 0 & 1 \\
\hline Total & 168 & (35) & 160 & (26) & 126 & (14) & 106 & (7) & 39 (7) & 39 (4) & 5 & 7 \\
\hline
\end{tabular}

when there was a family history of glaucoma, the anterior chamber depth was measured with the Haag-Streit attachment, and applanation tonometry was performed. In selected cases gonioscopy was also carried out. The questionnaire about place of longest residence, schooling, occupation, and snow blindness was then completed.

It was originally planned to attempt an assessment of diet for each individual, but after advice from a dietician it was concluded that the results would be too unreliable to have any value. We did, however, obtain information from the manager of the earlier Hudson Bay store as to the type of store goods which had been available to the population over the last 35 years.

\section{KERATOMETRY AND AXIAL LENGTH}

The horizontal radius of curvature of each eye was measured with the keratometry attachment to the Diag slit-lamp microscope (Clement Clarke International). Axial length was estimated by a modification of an optical method previously described (Perkins et al., 1976). The method consists of measuring the distance between the corneal image of 2 illuminated slits positioned so that the eye rotates through an angle of 40 degrees in looking from one slit to the other. In the original method the corneal reflexes were photographed, and subsequently the distance between the 2 reflexes was measured on the film. For survey purposes the camera was replaced by a measuring microscope with an illuminated scale in the eyepiece. The position of the corneal image within the eye was taken as a point half the radius of curvature of the cornea along the optic axis. A comparison of this method with ultrasonography (Grey et al., 1977) had shown that the anterior radius of rotation of the globe was greater than the posterior radius by approximately half the radius of curvature of the cornea and allowance for this was made in the calculation of axial length. The results suggest that this empirical correction may be too large, and emphasis will be placed on comparisons of the lengths obtained rather than the absolute values.

\section{REFRACTION}

The persons were refracted by means of retinoscopy and when possible subjective testing. We performed retinoscopy without cycloplegia but taking care that fixation was maintained on an object $6 \mathrm{~m}$ away. Cycloplegia was used only in a small number of children, particularly when cover testing (done routinely) suggested a squint.

\section{EXTERNAL EXAMINATION}

Particular attention was paid to the presence or absence of epiblepharon, pinguecula, pterygium, corneal scarring, and spheroidal degeneration, and the results of this part of the survey will be reported later.

\section{Results}

A total of 650 members of the population were seen, representing $87 \%$ of those in residence. This included a number of children who were in a residential school at Northwest River and were examined in the Hospital at Northwest River before the team went to Nain. The age, sex, and racial structure of the population is shown in Table 1, and the figures in brackets indicate those members of the population who were not screened. Fig. 1 shows the age distribution of the population. From Table 1 it can be seen that the sample screened is representative of the total population except for a deficit of young male Inuits. 


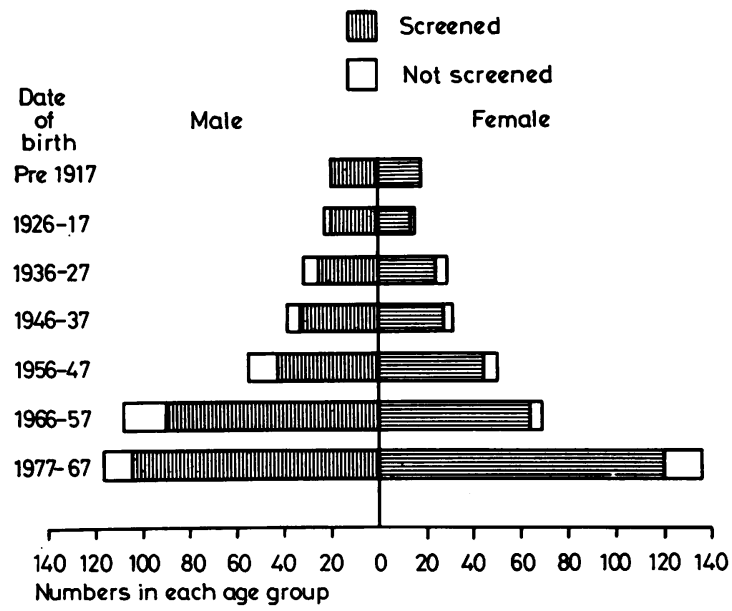

Fig. 1 Age and sex distribution of the population of Nain in 1977, combining the figures for the racial groups

Table 2 Incidence of refractive errors

\begin{tabular}{|c|c|c|c|}
\hline Refraction & Inuit & Mixed & Caucasian \\
\hline-5.00 & 4 & 1 & 0 \\
\hline$-4 \cdot 50$ & 1 & 0 & 0 \\
\hline$-4 \cdot 00$ & 1 & 0 & 0 \\
\hline-3.50 & 0 & 3 & 0 \\
\hline-3.00 & 0 & 1 & 1 \\
\hline$-2 \cdot 50$ & 7 & 3 & 1 \\
\hline-2.00 & 4 & 4 & 1 \\
\hline-1.50 & 3 & 5 & 1 \\
\hline-1.00 & 4 & 6 & 4 \\
\hline-0.50 & 12 & 17 & 2 \\
\hline-0.25 & 14 & 11 & 5 \\
\hline Plano & 27 & 26 & 9 \\
\hline+0.25 & 55 & 31 & 17 \\
\hline+0.50 & 46 & 25 & 6 \\
\hline+1.00 & 60 & 49 & 11 \\
\hline+1.50 & 17 & 11 & 7 \\
\hline+2.00 & 8 & 3 & 3 \\
\hline+2.50 & 3 & 3 & 0 \\
\hline+3.00 & 9 & 0 & 1 \\
\hline+3.50 & 1 & 0 & 1 \\
\hline+4.00 & 0 & 0 & 1 \\
\hline+4.50 & 1 & 0 & 0 \\
\hline+5.00 & 4 & 1 & 1 \\
\hline Total & 281 & 200 & 72 \\
\hline
\end{tabular}

\section{REFRACTIVE ERRORS}

The distribution of refractions of all right eyes (expressed as equivalent spheres) is shown in Table 2. The general pattern is similar in all 3 racial groups, and low degrees of hypermetropia account for approximately $60 \%$ of refractive errors in each group. The great majority of the myopes had low refractive errors (less than -3.0 D) and the incidence was higher in females $(57 \%)$ than in males $(43 \%)$. The refractions divided into myopia $(\geqslant-0.25 \mathrm{D})$, emmetropia $( \pm 0.25 \mathrm{D})$, and hypermetropia $(\geqslant 0.25$ D) for the 3 ethnic groups and the total population are shown in Table 3. There is a higher percentage of myopes in the Mixed group and the difference in percentage between the Mixed and Inuit is just significant $\left(\chi^{2}=4.18,0.05>P>0.02\right)$.

Figures for the distribution of refractive errors in the floating population (Caucasian nurses, technicians, teachers, etc.) are given separately in Table 3, and it is interesting to note that $50 \%$ were myopic. The floating population have not been included in any subsequent analysis.

The distribution of myopia $(\geqslant-0.25 \mathrm{D})$ by date of birth and race is shown in Table 4 and Fig. 2. The incidence rises with age, reaching peaks in those born during 1942-56, that is, those aged between 20 and 35 at the time of screening. The percentage incidence then drops sharply for those born in the preceding decade (1932-41) and then rises in the Mixed and Caucasian populations. As will be discussed later, the myopia in some of the older people was found to be associated with pathological changes in the cornea or lens. In Fig. 3 the results from all 3 races have been combined, and the graph clearly shows the sharp rise in incidence of myopia in those born after 1941.

A comparison of the incidence of myopia in the total population for those born between 1942 and 1961 (thus excluding children of 16 whose refraction may continue to change with growth) and those born before 1942 is shown in Table 5, and the difference between the age groups is statistically significant $\left(\chi^{2}=6.3,0.02>P>0.01\right)$.

Table 6 shows a similar comparison for the 3

Table 3 Distribution of refractive errors by racial group

\begin{tabular}{lccc}
\hline & $\begin{array}{l}\text { Myopia } \\
\geqslant 0.25 D\end{array}$ & $\begin{array}{c}\text { Emmetropia } \\
< \pm 0.25 D\end{array}$ & $\begin{array}{l}\text { Hypermetropia } \\
\geqslant+0.25 D\end{array}$ \\
\hline Inuit & $50(17.8 \%)$ & $27(9.6 \%)$ & $204(72.6 \%)$ \\
Mixed & $51(25.5 \%)$ & $26(13.0 \%)$ & $123(61.5 \%)$ \\
Caucasian & $15(20.8 \%)$ & $9(12.5 \%)$ & $48(66.7 \%)$ \\
Totals & $116(21.0 \%)$ & $62(11.2 \%)$ & $375(67.8 \%)$ \\
Floating population $10(50.0 \%)$ & $2(10.0 \%)$ & $8(40.0 \%)$ \\
\hline
\end{tabular}


races separately, but only in the Inuit is there a significant difference in the incidence of myopia in the 2 age groups.

The fact that some of the older population were myopic raises the question whether genetic factors could be involved. Fortunately a recent census of

Table 4 Incidence of myopia $(\geqslant 0 \cdot 25 \mathrm{D})$ by age and racial group

\begin{tabular}{|c|c|c|c|c|c|c|}
\hline \multirow{3}{*}{$\begin{array}{l}\begin{array}{l}\text { Date of } \\
\text { birth }\end{array} \\
1972-77\end{array}$} & \multicolumn{6}{|c|}{ Number and $\%$ of myopic eyes } \\
\hline & \multicolumn{2}{|c|}{ Inuit } & \multicolumn{2}{|c|}{ Mixed } & \multicolumn{2}{|c|}{ Caucasian } \\
\hline & 0 & $0.0 \%$ & 1 & $11 \cdot 1 \%$ & 1 & $16.7 \%$ \\
\hline $1967-71$ & 3 & $5 \cdot 1 \%$ & 9 & $17 \cdot 3 \%$ & 1 & $12 \cdot 5 \%$ \\
\hline $1962-66$ & 11 & $20 \cdot 0 \%$ & 7 & $24 \cdot 1 \%$ & 2 & $28.6 \%$ \\
\hline $1957-61$ & 9 & $31 \cdot 0 \%$ & 8 & $32 \cdot 0 \%$ & $\mathbf{0}$ & $0.0 \%$ \\
\hline $1952-56$ & 8 & $40.0 \%$ & 6 & $28.6 \%$ & 3 & $42.9 \%$ \\
\hline $1947-51$ & 6 & $35 \cdot 3 \%$ & 5 & $31 \cdot 3 \%$ & 1 & $25.0 \%$ \\
\hline $1942-46$ & 5 & $33.3 \%$ & 5 & $62.5 \%$ & 2 & $18.2 \%$ \\
\hline $1937-41$ & 1 & $6.7 \%$ & 1 & $16.7 \%$ & 0 & $0.0 \%$ \\
\hline $1932-36$ & 3 & $16.7 \%$ & 0 & $0.0 \%$ & 0 & $0.0 \%$ \\
\hline $1927-31$ & 1 & $11 \cdot 1 \%$ & 0 & $0.0 \%$ & 2 & $50.0 \%$ \\
\hline $1922-26$ & 1 & $11 \cdot 1 \%$ & 4 & $36.4 \%$ & 1 & $33 \cdot 3 \%$ \\
\hline $1917-21$ & 0 & $0.0 \%$ & 2 & $50.0 \%$ & 1 & $50.0 \%$ \\
\hline pre-1917 & 2 & $11 \cdot 1 \%$ & 3 & $50.0 \%$ & 1 & $16.7 \%$ \\
\hline
\end{tabular}

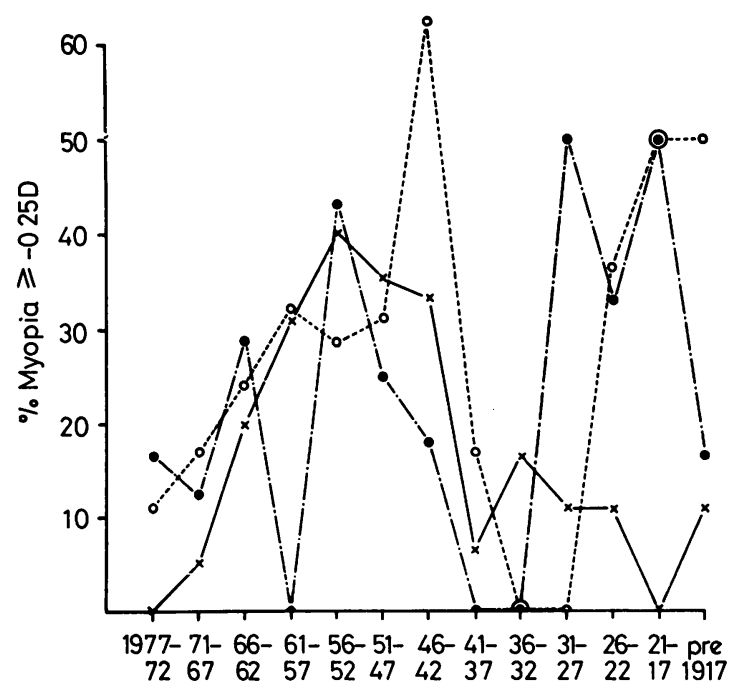

Fig. 2 Percentage of each age group with myopia equal to or greater than $-0 \cdot 25$ dioptres, according to racial origin. Inuit $\mathrm{X}-\mathrm{X}$. Mixed $\mathrm{O}---\mathrm{O}$. Caucasian $-\cdots$ the population was available, and from this and the help of the nursing staff and interpreters it was possible to construct family trees which included most of the myopes. From this, it transpired that 76 myopes came from 20 families in which myopia was present in 2 or more generations; in 11 there was a more doubtful family history, and there was no family history in 16.

According to Sorsby and Benjamin (1973) the ocular components which are genetically determined are axial length and corneal curvature over

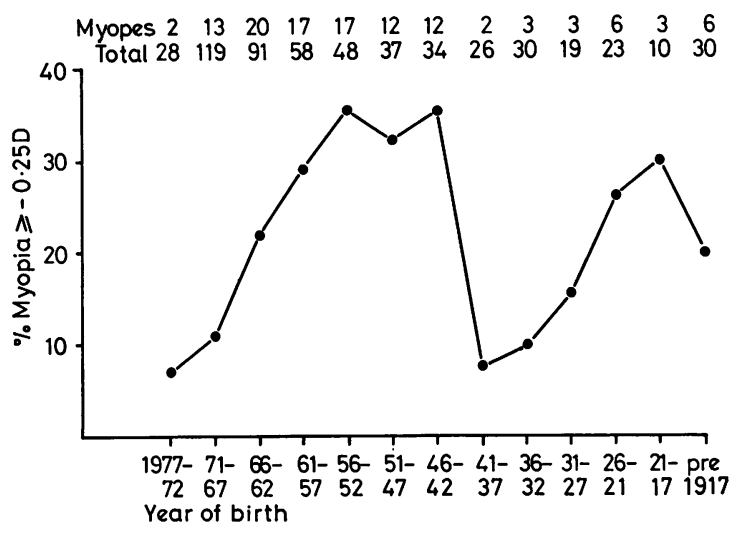

Fig. 3 Percentage of population in each 5-year age group with myopia equal to or greater than -0.25 dioptres, combining the results for the racial groups

Table 5 Incidence of myopia in total population over the age of 16 years

\begin{tabular}{llll}
\hline Date of birth & No. of myopes & No. of non-myopes & $\%$ myopia \\
\hline $1942-61$ & 58 & 177 & $24.7 \%$ \\
Pre-1942 & 23 & 138 & $16.7 \%$ \\
\hline
\end{tabular}

Table 6 Incidence of myopia by racial group over the age of 16 years

\begin{tabular}{lllll}
\hline Race & Date of birth & $\begin{array}{l}\text { No. of } \\
\text { myopes }\end{array}$ & $\begin{array}{l}\text { No. of } \\
\text { non-myopes }\end{array}$ & $\%$ myopia \\
\hline Inuit & $1942-61$ & $28 *$ & 81 & $25 \cdot 7 \%$ \\
& Pre-1942 & 8 & 73 & $9 \cdot 9 \%$ \\
\multirow{3}{*}{ Mixed } & $1942-61$ & 24 & 70 & $25 \cdot 5 \%$ \\
& Pre-1942 & 10 & 40 & $20 \cdot 0 \%$ \\
\multirow{2}{*}{ Caucasian } & $1942-61$ & 6 & 26 & $18 \cdot 8 \%$ \\
& Pre-1942 & 5 & 25 & $20 \cdot 0 \%$ \\
\hline
\end{tabular}

$\left({ }^{*} \chi^{2}=7 \cdot 56, P<0 \cdot 01\right)$ 
the range of $\pm 4.00 \mathrm{D}$, and these findings were confirmed in a study of Greenland Eskimos by Alsbirk (1977). We therefore calculated the correlation coefficients for refraction and axial length for 76 families on which data was available. The results are shown in Table 7, and it can be seen that there is no correlation between the parents and children for refraction but there are significant correlations for axial length. Proof of a purely genetic determination theoretically requires a correlation coefficient of 0.5 , and, although we found no correlations as high as this, the figures for fathers and daughters, and fathers and sons are very suggestive of a genetic component in axial length.

\section{AXIAL LENGTH}

As previously stated, the calculation of axial length included an empirical factor which in a previous series of measurements on Caucasian eyes seemed to give a better correlation between the results of the optical method and ultrasonography. The results shown below suggest that the calculated values are too low, and emphasis should be placed on comparisons rather than actual values.

The mean axial lengths for right eyes for which satisfactory readings were obtainable are given in Table 8 for the 3 racial groups.

There are significant differences between the means for the 3 racial groups, the Caucasians having the longest and the Inuit the shortest mean axial length. These results might be biased owing to the larger number of young people in the Inuit and Mixed groups, but a comparison between the mean axial

Table 7 Correlation of refraction and axial length between parents and children

\begin{tabular}{lrrrrr}
\hline & \multicolumn{2}{l}{ Refraction } & \multicolumn{2}{l}{ Axial length } \\
\cline { 2 - 6 } & r & $P$ & r & $P$ \\
\hline Fathers and sons & -0.074 & 0.24 & 0.317 & $<0.001$ \\
Fathers and daughters & 0.059 & 0.33 & 0.357 & $<0.004$ \\
Mothers and sons & 0.007 & 0.47 & 0.027 & 0.40 \\
Mothers and daughters & -0.054 & 0.32 & 0.197 & $<0.044$ \\
Parents and children & -0.014 & 0.40 & 0.196 & $<0.001$ \\
\hline
\end{tabular}

Table 8 Mean axial lengths of all right eyes by racial groups

\begin{tabular}{lrrr}
\hline Race & No. & Mean $A L$ & $\begin{array}{l}\text { Standard } \\
\text { deviation }\end{array}$ \\
\hline Inuit & 258 & $21.87 \mathrm{~mm}$ & \pm 0.9905 \\
Mixed & 188 & $22.26 \mathrm{~mm}$ & \pm 0.9271 \\
Caucasian & 68 & $22.59 \mathrm{~mm}$ & \pm 1.0211 \\
\hline
\end{tabular}

length of the eyes of Inuit and Mixed subjects over the age of 20 (Table 9) shows that they are significantly shorter than Caucasian eyes $(P<0.046)$.

There are also very significant differences in the mean axial length for different refractive states in the Inuit and Mixed group. The myopic eyes have the largest axial length (Table 10).

This was not so for the Caucasians, in whom the emmetropes had the longest mean axial length of $22.67 \mathrm{~mm}$ and the hypermetropes a mean of 22.36 $\mathrm{mm}$. The greater length of the emmetropic eyes could have been due to the preponderance (17 to 2) of male eyes in this group.

\section{BODY HEIGHT}

As would be expected, there was a significant correlation between axial length and age in the first 2 decades. We were interested, however, in any possible correlation between axial length and body build, as we had gained the impression that the older Inuit and Mixed who were rather short also had short eyes. Analysis showed that this impression was correct not only for both male and female adults of Inuit and Mixed subjects but also for male Caucasians as shown below (Table 11). The mean

Table 9 Mean axial lengths of right eyes of Inuit and Mixed populations compared with Caucasian eyes (Subjects over the age of 20 years)

\begin{tabular}{lrll}
\hline Race & No. & Mean $(\mathrm{mm})$ & Standard deviation \\
\hline $\begin{array}{l}\text { Inuit and } \\
\text { Mixed }\end{array}$ & 161 & 22.23 & \pm 0.9524 \\
Caucasians & 63 & 22.59 & \pm 1.0211 \\
\hline
\end{tabular}

Table 10 Mean axial lengths in different refractive states for Inuit and Mixed combined

\begin{tabular}{rcll}
\hline Refraction & No. of eyes & Mean $A L(\mathrm{~mm})$ & Standard deviation \\
\hline$\geqslant-0.50 \mathrm{D}$ & 75 & 22.69 & \pm 0.935 \\
$\pm 0.50 \mathrm{D}$ & 158 & 22.11 & \pm 0.899 \\
$\geqslant+0.50 \mathrm{D}$ & 214 & 21.75 & \pm 0.936 \\
\hline
\end{tabular}

Table 11 Axial length and height

\begin{tabular}{llllc}
\hline Race & Sex & $\begin{array}{l}\text { Correlation } \\
\text { coefficient }\end{array}$ & Significance & $\begin{array}{l}\text { No. of } \\
\text { eyes }\end{array}$ \\
\hline $\begin{array}{c}\text { Inuit and } \\
\text { Mixed }\end{array}$ & Males & $r=0.533$ & $\mathbf{P}<0.001$ & 104 \\
$\begin{array}{c}\text { Caucasian } \\
\begin{array}{c}\text { Inuit and } \\
\text { Mixed }\end{array}\end{array}$ & Males & $r=0.415$ & $\mathbf{P}<0.025$ & 30 \\
$\begin{array}{c}\text { Caucasian } \\
\text { Females }\end{array}$ & Females & $r=0.281$ & $\mathbf{P}<0.01$ & 97 \\
\hline
\end{tabular}




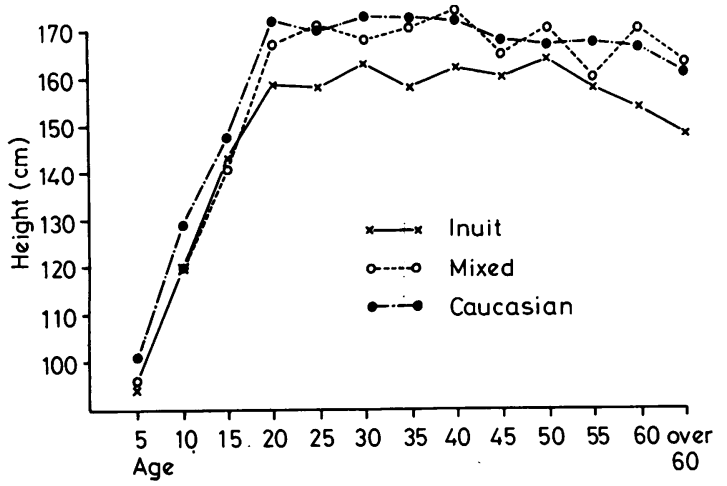

Fig. 4 Mean heights of males, according to racial origin, for each age group

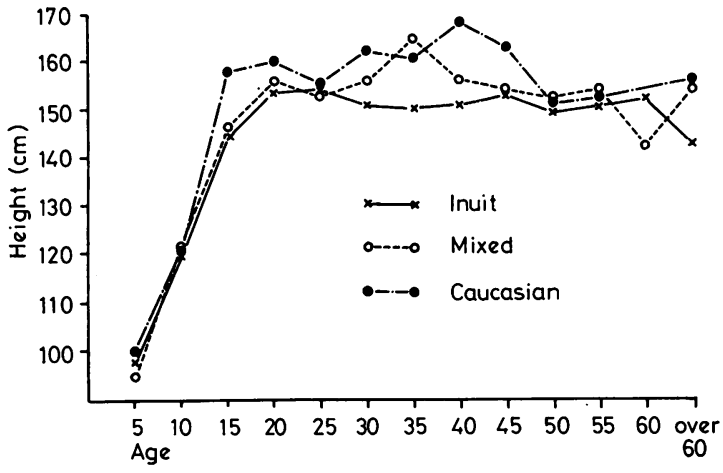

Fig. 5 Mean heights of females, according to racial origin, for each age group

heights for males and females of each group by age are shown in Figs. 4 and 5.

The mean height of the Inuit and Mixed population in the third and fourth decades is greater than that of those over 40 (males by $7.24 \mathrm{~cm}$, females by $3.53 \mathrm{~cm}$ ). Further analysis showed that there was a significant positive correlation between height and axial length in this population over the age of 20 (Table 11).

\section{ASTIGMATISM}

Astigmatism of more than one dioptre was found more frequently among the Inuit than the Mixed and Caucasians (Table 12).

Corneal disease (old tuberculous interstitial keratitis or other corneal scars) might have caused 6 cases in the Inuit and 2 cases in the Mixed. The astigmatism was against the rule in half the Inuit eyes and in 10 out of the 12 Mixed race eyes. The highest error was $-3.00 \mathrm{sph}-7.00 \mathrm{D}$ cyl in a patient with severe corneal scarring.
Lesser degrees of astigmatism, 0.5 to $1.00 \mathrm{D}$, were also more common in the Inuit (Table 13).

\section{SCHOOL PERFORMANCE}

In view of suggestions that myopia is the result of the extra accommodative effort required in school work we compared the scholastic achievement of myopes $(-0.50 \mathrm{D}$ or more) with hypermetropes $(+0.50 \mathrm{D}$ or more $)$ in the Inuit and Mixed races born between 1942 and 1962 (age from 15 to 35) (Table 14). From Table 14 it will be seen that the mean school grade of the Inuit is higher for myopes than hypermetropes, but this is not so for the Mixed population.

A comparison of those myopes achieving grade 8 or better with emmetropes and hypermetropes combined in the total population over the age of 15 is shown in Table 15.

Table 12 Astigmatism over $1 \mathrm{D}$ (right eyes)

\begin{tabular}{llllll}
\hline Race & $\begin{array}{l}\text { Total } \\
\text { refractions }\end{array}$ & $\begin{array}{l}\text { Astig- } \\
\text { matism }\end{array}$ & $\begin{array}{l}\text { Against } \\
\text { the rule }\end{array}$ & $\begin{array}{l}\text { Astig- } \\
\text { matism }\end{array}$ & $\begin{array}{l}\text { Mean } \\
\text { error }\end{array}$ \\
\hline Inuit & 281 & 32 & 16 & $11.39 \%$ & 3.23 D \\
Mixed & 200 & 12 & 10 & $6.00 \%$ & 2.35 D \\
Caucasian & 74 & 4 & 3 & $5.56 \%$ & $2.00 \mathrm{D}$ \\
\hline
\end{tabular}

Table 13 Astigmatism 0.50 to $1.00 \mathrm{D}$

\begin{tabular}{llllll}
\hline Race & $\begin{array}{l}\text { Total } \\
\text { refraction }\end{array}$ & Astigmatism & $\begin{array}{l}\text { Against } \\
\text { the rule }\end{array}$ & $\%$ Astigmatism \\
\hline Inuit & 281 & 23 & 20 & $8 \cdot 19$ \\
Mixed & 200 & 11 & 3 & $5 \cdot 5$ \\
Caucasian & 74 & 3 & 2 & 4.05 \\
\hline
\end{tabular}

Table 14 Mean school grade achieved by myopes and hypermetropes aged 15 to 35

\begin{tabular}{lll}
\hline & Inuit & Mixed \\
\hline Myopes & $7.37(19)$ & $8.41(17)$ \\
Hypermetropes & $6.96(26)$ & $8.67(21)$ \\
\hline
\end{tabular}

Table 15 Achievement of grade 8 by ethnic group and refraction

\begin{tabular}{lrll}
\hline Race & Grade & Myopes $(\geqslant-0.50 \mathrm{D})$ & Other refractions \\
\hline Inuit & 8 & 14 & 34 \\
& $<8$ & 13 & 93 \\
& $\% 8$ & 51.9 & $31 \cdot 17$ \\
Mixed & 8 & 16 & 46 \\
& $<8$ & 11 & 106 \\
& $\% 8$ & 59.26 & 34.64 \\
\hline
\end{tabular}


It can be seen from this table that a higher proportion of myopes from both groups achieved grade 8 or better and these differences are statistically significant (for Inuit $\chi^{2}=6.53,0.027>P>0.01$ and for the Mixed $\left.\chi^{2}=8.51 \mathrm{P}<0.01\right)$. These results could be biased because the older population ( $>35$ years) in whom the incidence of myopia was lower did not have the same educational opportunities as the younger age groups and would have been unable to attend school long enough to achieve grade 8 .

\section{Discussion}

One of the first problems encountered in this survey was the division of the population into ethnic groups. It is sometimes stated that there are no pure Inuit in Labrador. We believe that this is not true, as some of the people in Nain had migrated from further north and were of the same stock as the population of Baffin Island. This area of Labrador has been visited by Europeans for hundreds of years, and it is impossible to be sure that some of the people classified as Inuit did not have a few Caucasian genes. The division into Inuit, Mixed, and Caucasian was made in consultation with the interpreters and older inhabitants and may not be completely accurate. If the family history suggested that more than 1 great grandparent was Caucasian they were classified as Mixed.

Living conditions in Nain are relatively good. Housing for most families is adequate. Electricity is available, and the majority of families have a telephone and television set. There is little employment locally except for the traditional fishing and employment in the fish processing plant in the summer and hunting in the winter. This does mean, however, that natural protein is available fairly freely, although it was clear from conversations with storekeepers that a wide range of store food has become available and used over the last 30 years. Before 1942 the main foods bought from Hudson Bay Company Store comprised flour and molasses, but with the advent of the Government Store in 1946 an increasing variety of imported food provided a considerable proportion of the diet-mainly in the form of carbohydrates.

\section{MYOPIA}

The tables presented show that myopia occurs more frequently in the Inuit and Mixed population between the ages of 10 and 40 than in the older population, though the difference is not so striking as that reported from other communities-the Eskimos in Barrow, Alaska, for example (Young et al., 1969). It is interesting to see that the Caucasians also showed a similar pattern in the incidence of myopia with age. They have been exposed to very similar environmental and dietetic influences as the other racial groups. In both the Mixed and Caucasian groups the incidence of myopia in the subjects over the age of 40 was rather high and prompted a closer look at the records from these individuals to see if there was any ocular pathology which could account for the myopia. This showed that 6 out of the 9 Mixed race myopes had a marked degree of Labrador keratopathy (spheroidal degeneration of the cornea) and 2 others had lesser changes. All 5 Caucasian myopes over the age of 40 had marked keratopathy and 1 also had chronic simple glaucoma. Even among the 7 Inuit myopes over the age of 40, 5 had keratopathy (1 also had cataract) and the other 2 had corneal scars from old keratitis. One of the latter had very distorted corneae with the highest myopic refractive error in the whole population (-3.00 D Sph -7.00 D cyl).

The axial lengths of the older Inuit and Mixed race eyes also suggested that the myopia was not axial in many cases. In only 7 out of 16 Inuit and Mixed was the axial length greater than the mean for emmetropic eyes.

These findings suggest that ocular pathology could account for some of the apparent myopia in the older age groups, and if these eyes with corneal lesions and/or lens changes are excluded the preponderance of myopia in the younger age groups becomes more significant.

Woodruff and Samek (1977) pointed out that the cylindrical component of the refractive error may cause the equivalent sphere to be of negative sign. Examination of the astigmatic errors in our series showed that this was only true for 6 Inuit and 7 Mixed myopes of $-0.25 \mathrm{D}$ or more.

Astigmatic errors were commoner among the Inuit than in the other races and were more often against the rule.

The most marked difference in the age incidence of myopia occurs between those born between 1942 and 1946 and those born in the previous decade. This means that the rise in incidence of myopia coincides with the advent of a wider choice of foodstuffs available from the Government store, which suggests a dietary influence. However, it is also probable that more children born after 1942 had better educational opportunities and more intensive schooling than those born before 1942, so that in addition to a change in diet there is the possibility of increased close work playing a part.

The attempt to compare educational achievement with refraction was based on school grades, which may not be a very satisfactory method of assessing 
the amount of close work done. The results did show that a higher proportion of the myopic Inuits and Mixed subjects achieved grade 8 than emmetropes and hypermetropes. There is therefore some evidence to support the contention that educational achievement is higher in myopes or alternatively that myopia is more likely in those with higher educational achievement.

Axial length measurements showed that myopic eyes were significantly longer than emmetropic and hypermetropic eyes and that irrespective of refraction the mean axial length of eyes from the 3 racial groups were significantly different, the Inuit eyes being shortest and the Caucasian eyes being longest. These differences could be due to differences in body statue. Figs. 4 and 5 show that from the age of 30 the Caucasians are on average consistently taller than the Inuits. The Mixed group heights are closer to the Caucasian population than to the Inuit.

Although many of the myopes come from families in which myopia was present in 2 or more generations there was no correlation between refraction of parents and children. There was, however, a significant correlation between parents and children with regard to axial length.

The main object of the refractive survey was to examine the incidence of myopia to see if it supported suggestions that environmental factors could be responsible. Our results support previous studies in Indian and Eskimo populations showing an increase in simple myopia in the younger age groups and confirm that the myopic eyes are associated with a longer axial length than emmetropic and hypermetropic eyes.

It is generally agreed that refractive errors are not distributed normally as are other physical features such as height and weight but show an excess of emmetropia, which is brought about by an active process. Low degrees of ametropia can be looked upon as a failure of this process to produce emmetropia, and it is certainly possible that environmental factors could be involved. The fine adjustment of refraction is probably brought about by the refractive power of the lens, and if, for example, the lens does not flatten sufficiently during the growth of the eye the final refraction will be myopic. A greater degree of adjustment will be required to produce emmetropia if the axial length (which is genetically determined) departs from a median value. If the dioptric power of the lens remains too high (? as a result of excess accommodative effort) the eye will be myopic particularly if the axial length is on the long side.

Emmetropisation will be more difficult to obtain in a longer eye and any environmental factors which impede the process will have a greater effect. It is therefore possible to reconcile genetic and environmental factors by this hypothesis, and to suggest that the increased incidence of myopia in the younger generations is brought about by an environmental factor preventing complete harmonisation of the refractive components of the eye with a genetically determined longer axial length.

From the evidence available we cannot implicate any single environmental factor. There is some evidence that attendance at school might be a factor, but at the same time as schooling became more generally available there was an undoubted change in diet, with more store foods and carbohydrate providing an appreciable proportion of total food intake.

An additional factor which should also be considered is the possibility that eye size is linked to body stature. The younger age groups who have the highest incidence of myopia tend to be taller than the older population and will also tend to have longer axial lengths because they are taller. If emmetropisation is more difficult to achieve in longer eyes then myopia will result more often in the younger age groups.

It could be that better hygiene and a higher calorie diet has resulted in the younger population growing taller than their parents, with the penalty that their eyes are longer and therefore more likely to become myopic. It could be argued, however, that the less striking excess of myopes in the Nain population compared with some other northern people is due to the fact that fishing and hunting still provides a higher proportion of protein in the diet than would be obtained in populations relying almost entirely on store food.

Woodruff and Samek (1976) found a lower incidence of myopia among the Eskimos of Belcher Island, where fish and game are more plentiful, than among more northern natives, where the protein intake is lower.

There is no evidence at the moment that the myopia in this population has resulted in any serious ocular complications. Retinal detachment is very rare among the native population of Labrador but as the risk of detachment is higher even in low myopes than in emmetropes and hypermetropes (Perkins, unpublished data) it will be interesting to see whether more cases are seen in future. No typical myopic crescents or other fundus changes suggesting myopic degeneration were seen in the population examined.

We are most grateful for all the facilities put at our disposal by the International Grenfell Association and the financial support from the E. A. Baker Fund of the Canadian National Institute for the Blind. We owe a special debt of gratitude to 
the nursing staff at Nain under Miss S. Ambrose. Without their hard work and excellent relations with the population such a survey would have been impossible. We are also grateful for the co-operation of the interpreters and many older members of the population for their help with genealogies and general information about conditions in Nain. Our thanks are also due to the Computer Department of the Institute of Ophthalmology for the computer analyses, and to the Department of Audiovisual Communication for the graphs.

\section{References}

Alsbirk, P. H. (1977). Variation and heritability of ocular dimensions. Acta Ophthalmologica, 55, 443-455.

Boniuk, V. (1973). Refractive problems in native peoples. Canadian Journal of Ophthalmology, 8, 229-233.

Cass, E. (1973). A decade of northern ophthalmology. Canadian Journal of Ophthalmology, 8, 210-217.

Grey, R. H. B., Perkins, E. S., and Restori, M. (1977). Comparison of ultrasonic and photographic methods of axial length measurements of the eye. British Journal of Ophthalmology, 61, 423-427.

Morgan, R. W.. and Munro, M. (1973). Refractive problems in northern natives. Canadian Journal of Ophthalmology, 8, 226-228.

Perkins, E. S., Hammond, B., and Milliken, A. B. (1976). Simple method of determining the axial length of the eye. British Journal of Ophthalmology, 60, 266-270.

Sorsby, A., and Benjamin, B. (1973). Modes of inheritance of errors of refraction. Journal of Medical Genetics, 10, 161-164.

Woodruff, M. E., and Samek, M. J. (1976). The refractive status of Belcher Island Eskimos. Canadian Journal of Public Health, 67, 314-320.

Woodruff, M. E., and Samek, M. J. (1977). A study of the prevalence of spherical equivalent refractive states and anisometropia in Amerind populations in Ontario. Canadian Journal of Public Health, 68, 414-424.

Young, F. A., Leary, G. A., and Baldwin, W. R. (1969). The transmission of refractive errors within Eskimo families. American Journal of Optometry and Physiological Optics, 46, 676-685. 